\title{
Efficiency of modern geoinformation technologies application at survey works designing on inland waterways of Russia
}

\author{
Vladimir Karetnikov ${ }^{1}$, Sergey Rudykh ${ }^{1}$ and Aleksandra Ivanova ${ }^{1, *}$ \\ ${ }^{1}$ Admiral Makarov State University of Maritime and Inland Shipping, 198035, 5/7 Dvinskaya Street, \\ St. Petersburg, Russia
}

\begin{abstract}
Survey works on inland waterways can be contingently divided into two directions. The first ones are directed at maintaining the given dimensions of the waterway and are carried out with the use of technical fleet vessels, which includes the dredging fleet. At the same time the basis creation, the results verification and the control of the survey works implementation are carried out by the survey party. The main types of work here are surveying and trawling works, the implementation of which is carried out at the present time on the inland waterways of Russia using geoinformation technologies, which makes it possible to improve the quality and efficiency of their realization. Such an approach, firstly, has a positive effect on the implementation of the navigational hydrographic support system of navigators, including in the part of electronic cartography, and secondly, it allows to provide the survey works realization at the modern level. The most effective approaches and methods of modern geoinformation technologies application, implemented for the collection and processing of high-precision bathymetric information and positioning data to ensure the navigation safety on the inland waterways of the Russian Federation, are considered in the paper.
\end{abstract}

\section{Introduction}

About 100 000,00 kilometers of inland waterways (IW) are annually used for navigation purposes in Russia, of which almost 50 000,00 kilometers have guaranteed dimensions of the fairway and more than 60000,00 kilometers are serviced by means of navigation equipment (MNE). The task of safe navigation conditions ensuring on inland waterways is vested in the River Basins Administrations, which are subordinate organizations of The Federal Agency for Maritime and River Transport (Rosmorrechflot). To solve the problem of navigational conditions providing, the River Basins Administrations performs a complex of the survey works, maintaining the specified way dimensions and protecting fairways on the terrain with the navigational signs [1].

Survey work includes the maintenance of navigation equipment, survey works, dredging, channeling, rock removing work, trawling, as well as straightening and coast protection work.

\footnotetext{
* Corresponding author: ageevaalexandra.gumrf@gmail.com
} 
A significant length of inland waterways requires essential material and temporal costs for survey works implementation and navigational and hydrographic support of shipping.

One of the ways to optimize the costs for the production of survey works and navigational and hydrographic support, while performing the task of navigational conditions providing for the navigation safety in full, is the introduction of automated management systems of survey works production. Such automated systems are based on the use of modern telecommunication facilities and geoinformation technologies and allow to realize the continuous monitoring of operational parameters in the process of works production, maintaining the productivity of technical devices at a sufficiently high level [2].

The preparatory stage for the survey works design is hydrographic works and engineering surveys. The planned material is prepared by the survey parties of the River Basins Administrations branches, which basically perform the bulk of hydrographic, hydrological and topographical works.

Until recently, only automated surveying complexes were used for the production of hydrographic work on GDP, in which the depth measurement was carried out by a single beam echosounder, and positioning was performed using satellite radio navigation systems GLONASS / GPS / Galileo and their differential subsystems [3]. Such complexes allow performing depth measurements with fairly good productivity [4]. Herewith the movement of the survey vessel is carried out mainly by transverse passages, which causes considerable inconvenience to the navigator of the survey vessel, as a rule, only the control passages are carried out longitudinally. But a more significant drawback of such a survey is that the bottom relief remains completely unexplored in the zone between the survey passages. An object (underwater obstacle) can be located in this place. This underwater obstacle can be either of natural origin (large boulder, sunken wood, rock outcrop, etc.), either technogenic object (lost anchor, scrap metal, litter, garbage, etc.) [5]. Such natural and technogenic underwater obstacles can significantly threaten the navigation safety, therefore, in addition to depth surveys by single-beam echosounder, it is necessary to produce the works on continuous trawling of fairways by mechanical trawls of various designs (fig. 1) [6, 7].
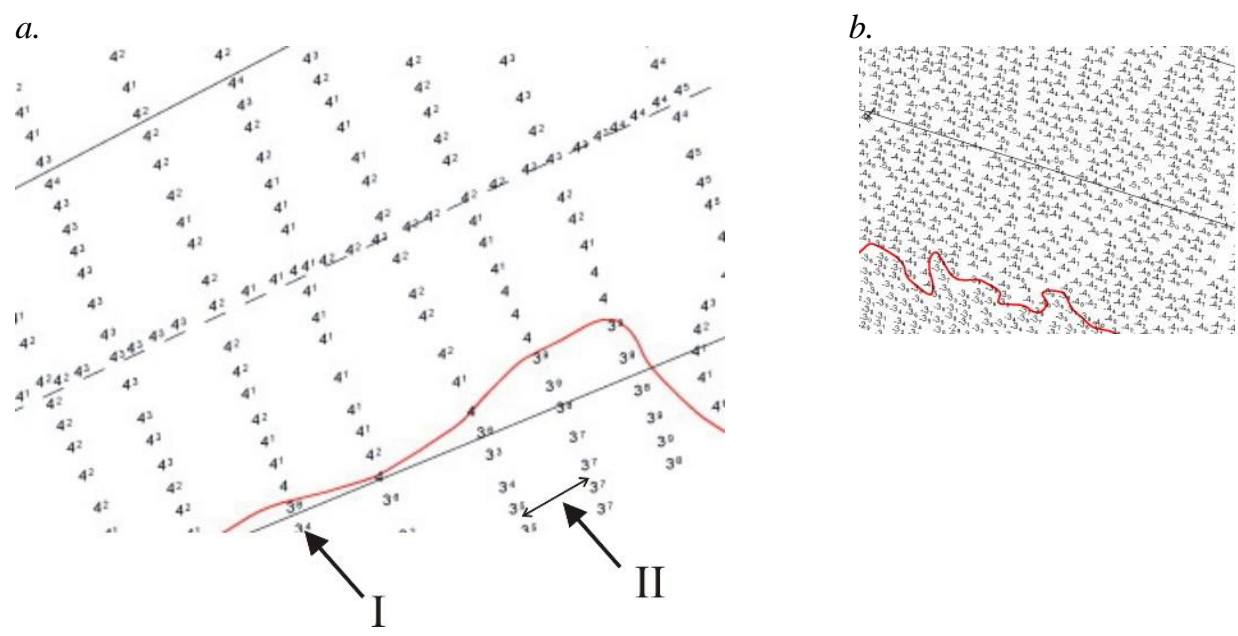

Fig. 1. Fragments of the depth surveys tablets: a) performed by an automated complex based on a single beam echo sounder (I - transverse survey passage, II - distance between passages); b) performed by an automated complex based on a multibeam echo sounder

Hydrographic works carried out by complexes based on multi-beam echosounders does not have such a disadvantage. In them, in contradistinction to single-beam echo sounders, the 
radiator transmits not one ultrasonic pulse, but a whole beam of pulses (up to several hundred simultaneously) that propagate in the water and are reflected from the bottom or underwater obstacles. Reflected rays are captured by the receiver unit of the echosounder antenna, digitized and transmitted to the echosounder processor unit to form an antenna directional pattern and processing. As a result, it becomes possible to perform a continuous survey of the bottom relief without omissions [8].

In such complexes, the bathymetric information directly during the depth survey is not displayed as a separate passage (as in a single beam) but it is dispayed as depths field within the width of the transducer's viewing area (fig. 2). The effective width of such band depends on the angle of exposure of the transducer's viewing area, and the survey detail depends on the number of transmited beams [9].

With the angle of exposure of 120-125 ${ }^{\circ}$, the capture width is about 3-4 depth values, which is 12-16 meters at the depth of 4 meters. In order to be able to uniquely and authentically judge the depths located at the ends of the passage, and there are no random omissions, the survey should be performed with some overlap of the passages that further reduces the useful capture width. 8-10 longitudinal passages will be required to be performed at such a width of the capture band for waterway with a guaranteed fairway depth of 4 meters and a width of 85 meters, which also requires considerable time costs and constant revs of survey vessel to reach the regular survey passage. This circumstance significantly complicated the production of hydrographic works.

\section{Results}

Taking into account the wishes of the River Basins Administrations to perform a continuous survey of navigable routes per the minimum number of passages, the multibeam echosounders manufacturers have found a very constructive solution. To increase the relatively small capture width by installation of two transducers with a viewing angle of up to 140 degrees at working in equidistant mode and up to 165 degrees at working in an equiangular mode on a common frame (bracket) located at some angle to the horizon in the plane of the viewing area (fig. 2,3).

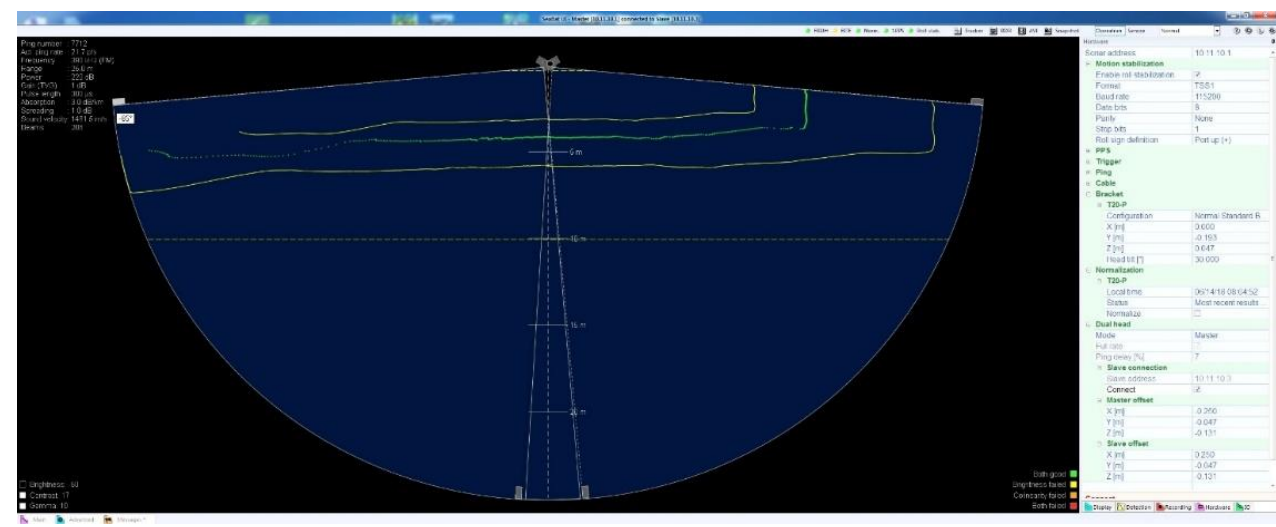

Fig. 2. The work of doubled transducers in equidistant mode 


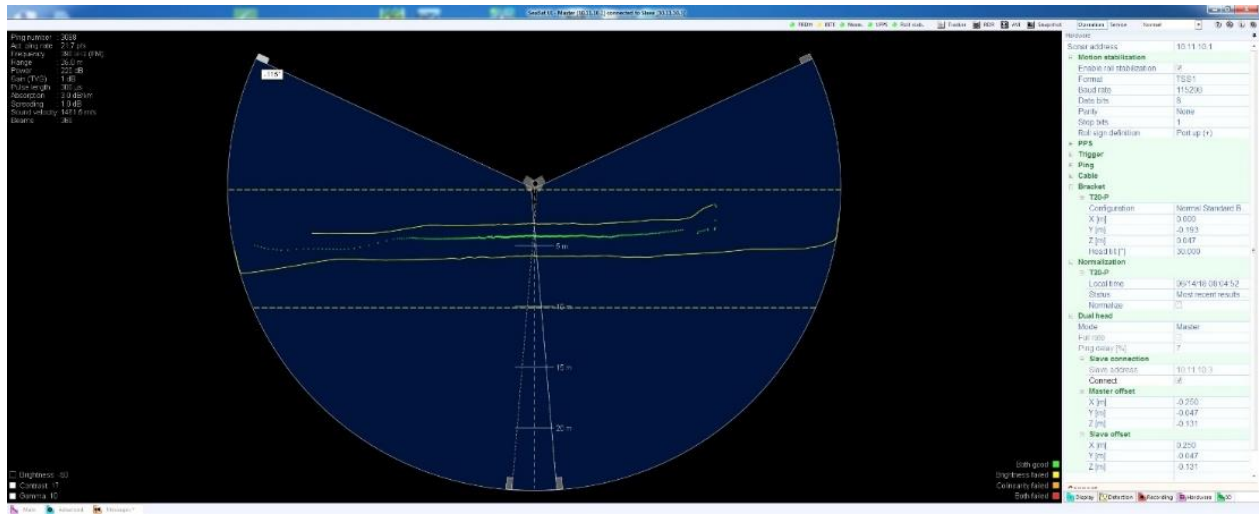

Fig. 3. The work of doubled transducers in equiangular mode

The software was also changed. The possibility of synchronous collection and subsequent processing of bathymetric information incoming simultaneously from both transducers appeared in this software. Thus the total viewing angle has reached $210^{\circ}$, and the number of ultrasonic pulses transmitted per time unit has been doubled and up to 512 beams began to be sent from each transducer. In addition, the detail has doubled in the overlapping zone of transducers, this circumstance has found wide application at pipelines inspection.

As a result, the useful capture width at the surveys production has increased to 10-12 depths, and in some cases up to 16 depths, which was repeatedly confirmed in practice. Such a useful capture bandwidth already makes it possible to perform a continuous survey of a 85 meter-wide fairway at a depth of 4 meters only for 2 longitudinal passages, and it is sufficient to perform one longitudinal passage on the deep alluvial sites for continuous survey.

The use of automated surveying complexes based on multi-beam echosounders with doubled transducers made it possible to reach a more progressive level of hydrographic works production and substantially increase the productivity of hydrographic works (fig. 4) [10, 11].

At the same time, the possibility of operative implementation of executive and control surveys of dredging slots and qualitatively evaluate of channel reorganization has appeared. It also became possible to perform a preliminary inspection of navigable ways, hydraulic structures, without resorting to a very expensive kind of work - diving examination.

a.

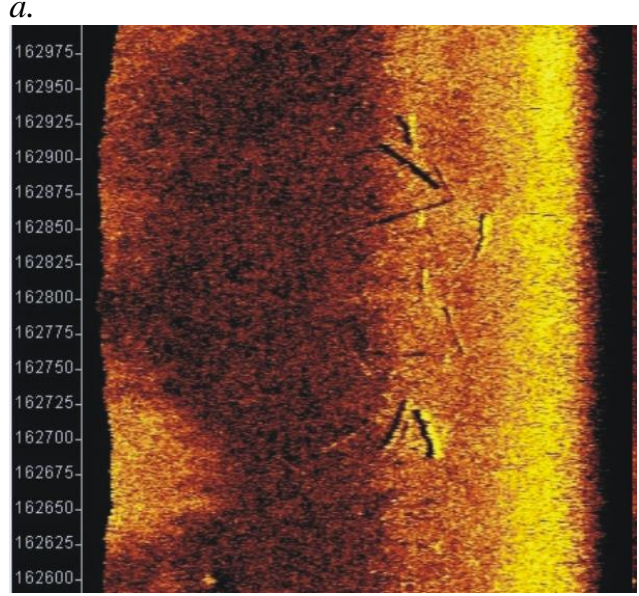

$b$.

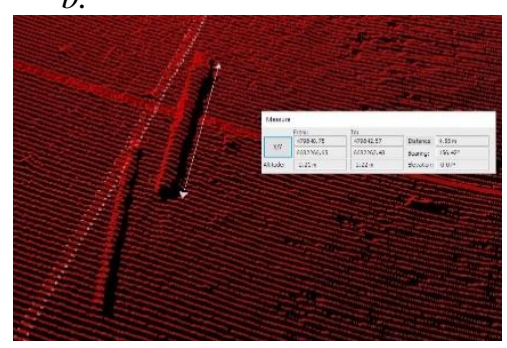

Fig. 4. The underwater obstacles (sunken wood) detected by the multi-beam echosounder: a) realtime sonar data; b) pings data and the identification of obstacles sizes 
Additional inclusion of inertial positioning and orientation systems and specialized software in automated surveying complexes allows to track the spatial position of the surveying vessel (motor boat) in real time directly during the survey. Due to such systems, the necessary amendments and corrections about the spatial position of the surveying vessel (motor boat), its speed, course are automatically entered into the bathymetric data coming from the transducers. These corrections and amendments take into account the influence of external conditions at the surveying works production, which include the influence of waving, wind or short-term loss of connection with satellites, etc. And the frequency of the emitted pulses sending of $50 \mathrm{~Hz}$ allows to ensure $100 \%$ bottom coverage during hydrographic works even at high speeds of the surveying vessel movement. High quality of the bathymetric data in the complexes based on multi-beam echo sounders can be obtained only with the use of profilers, which are assigned the role of ensuring the construction of a vertical profile of the sound propagation speed. The speed of sound propagation in water depends on the temperature of water, the pressure that varies with the reservoir depth, and also on the salinity of water, which is most relevant at hydrographic works implementation in the estuaries in the zone of pinch of saline water, where the density and salinity of water are irregularly distributed both vertically and horizontally (fig. 5).

\section{Speed of sound}

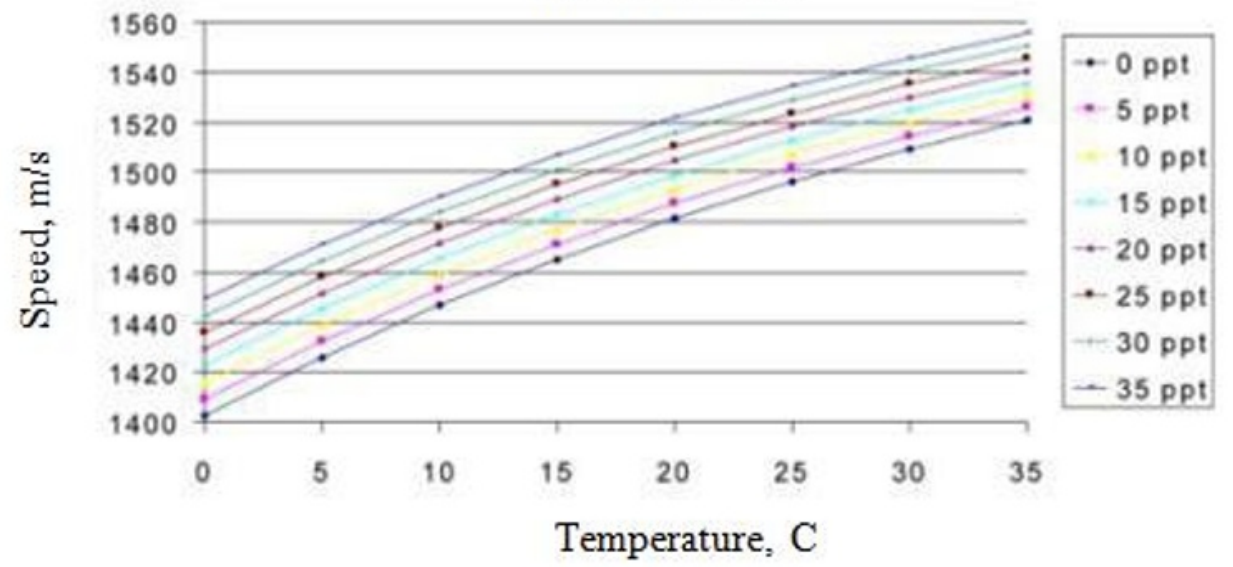

Fig. 5. The dependence diagram of the sound propagation speed in the surface layer from the temperature and salinity of water

A very convenient option of specialized software of automated surveying complexes is the ability to draw a digital 3D-model of bottom on the monitor screen with the assistance of special software that allows to process the data not only at a posteriori processing, but also in real time, and also evaluate the change of bottom relief. This option allows the operator to make timely changes to the settings of the hydroacoustic equipment to obtain the most complete bathymetric data, and in case of underwater obstacle detection which is difficult to identify, it allows to perform operatively the repeat, more detailed measurement with a better resolution.

The automated surveying complexes quite successfully cope with such tasks as search and detection of underwater obstacles and sunken objects, as well as determination of their location with high accuracy due to the means of navigation satellite systems. At the same time, the greatest positioning accuracy can be achieved when the complexes are operating in real time in the kinematics mode or post-processing mode (fig. 6, 7). 


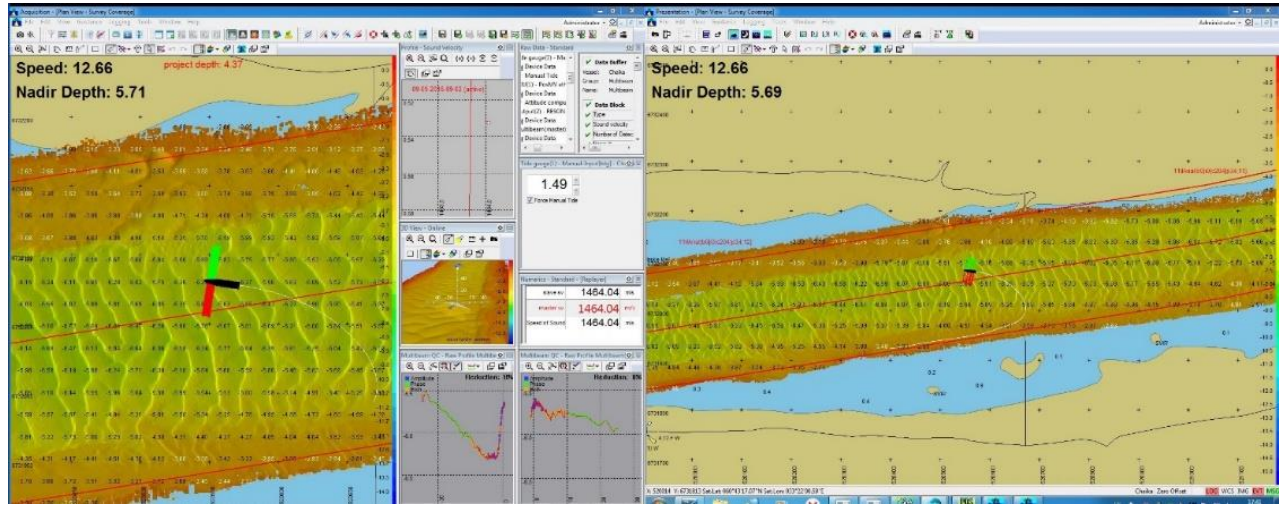

Fig. 6. The construction of a three-dimensional bottom relief model in real time at hydrographic works using complex based on the multibeam echo sounder with double transducers

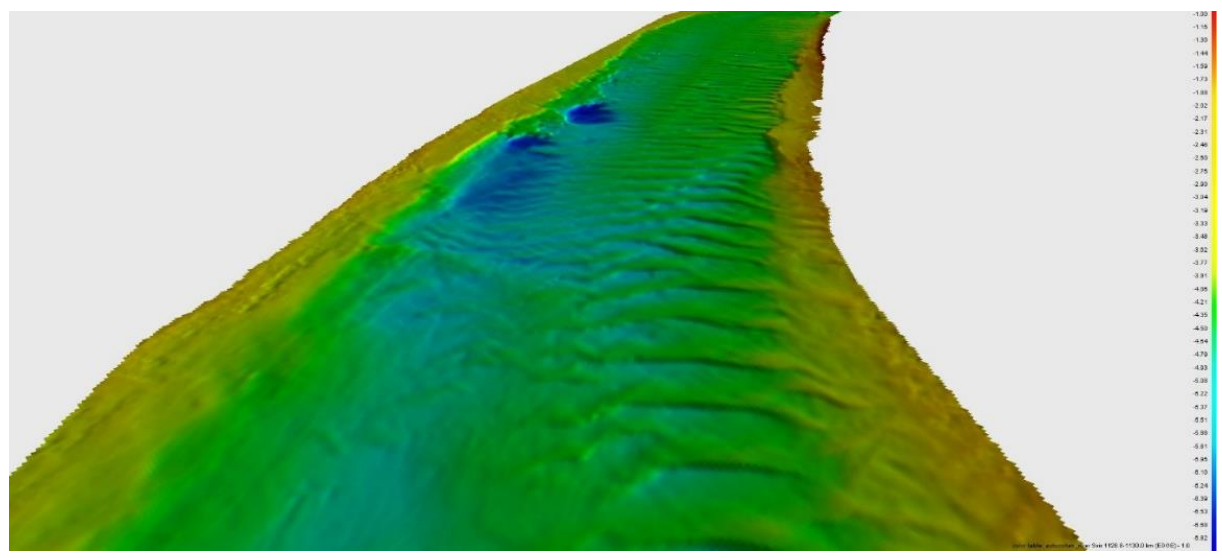

Fig. 7. Three-dimensional model of bottom relief formation of survey in postprocessing

The possibility of integration of the complex with high-resolution geodetic scanners allows to perform survey of the coastal relief with maximum productivity simultaneously with the production of hydrographic works (fig. 8) [12].

\section{Conclusions}

The automated surveying complexes application on inland waterways of the Russian Federation allows:

- to receive high-quality materials of hydrological surveys with high performance of works;

- to carry out a detailed investigation of the bottom relief sites;

- to examine and perform depth surveys before the beginning, during the production process and at the end of dredging;

- to search for and detect sunken objects and underwater obstacles;

- to perform hydroacoustic trawling;

- to carry out quality control of the production of underwater technical works. 


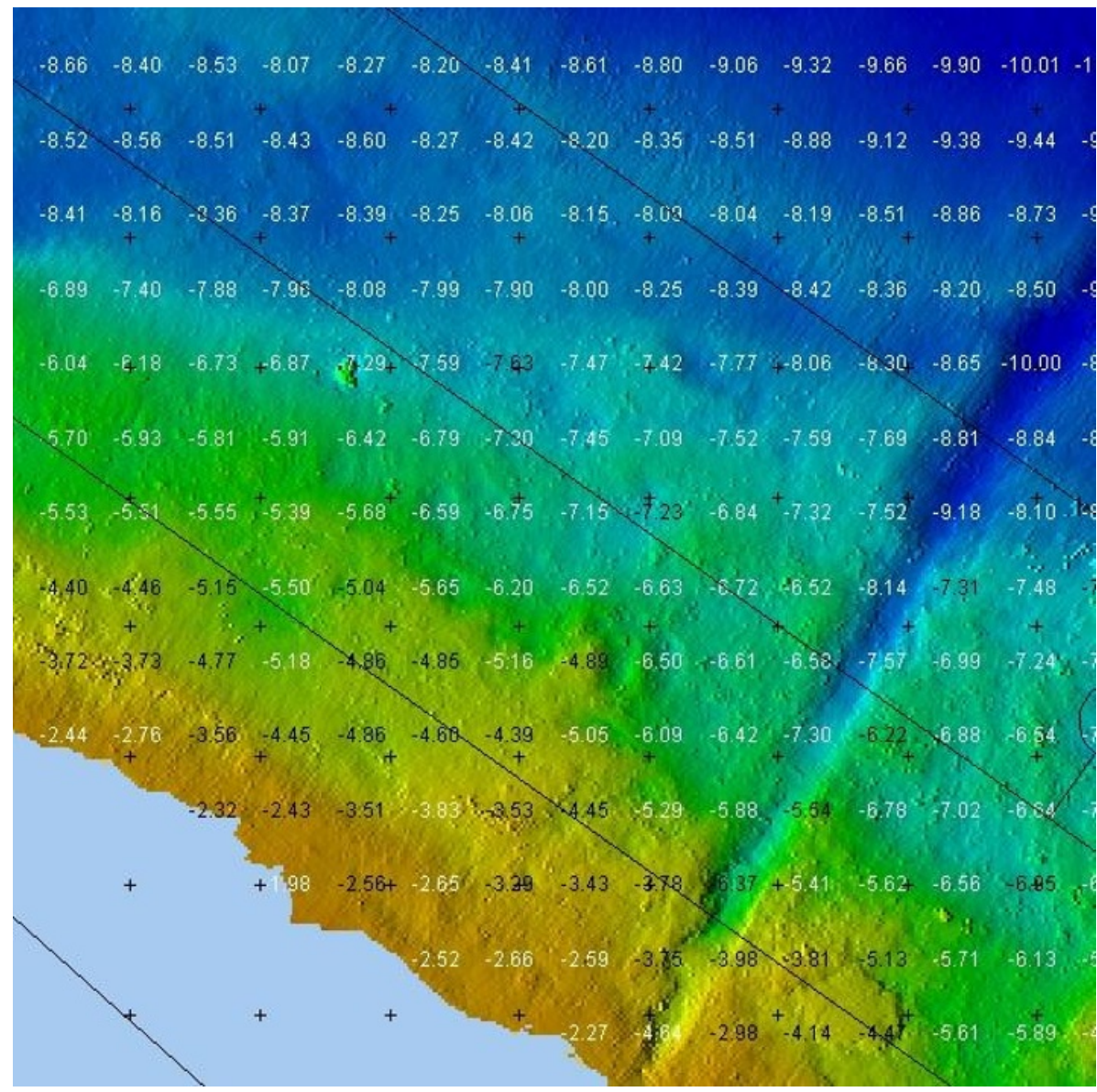

Fig. 8. Screenshot of the monitor of the complex based on the multibeam echosounder at the quality monitoring of the underwater trench device

Another important task for the navigation safety, which can be solved through the application of the above complexes, is the correction of navigational charts (including electronic ones) $[13,14]$. This task can be successfully and effectively solved even with such a significant length of Russia's inland waterways in the case of modern geoinformation technologies using.

\section{References}

1. S.V. Rudykh, Methodological foundations of the construction of infocommunication management systems of technical, auxiliary fleet and monitoring of navigation equipment means on inland waterways (St. Petersburg, Publishing house of the Polytechnic University, 2012)

2. A. Rahmani, A. Bouanani, A. Kacemi, K. Baba Hamed, J. Fundam. Appl. Sci., 9(2), 829-846 (2017). http://dx.doi.org/10.4314/jfas.v9i2.14

3. V.V. Karetnikov, A.A. Sikarev, Topology of differential fields and range of controlcorrecting stations of high-precision positioning on inland waterways (St. Petersburg, SPGUVK, 2008) 
4. W.H. McAnally, R. Kirby, S.H. Hodge, T.L. Welp, N. Greiser, P. Shrestha, D. McGowan, P. Turnipseed, J. Waterway, Port, Coastal, Ocean Eng., 142(2), 04015014 (2016). https://doi.org/10.1061/(ASCE)WW.1943-5460.0000301

5. K. Chakraborty, M.P.M. Sahoo, Procedia Engineering, 116, 1063-1071 (2015). https://doi.org/10.1016/j.proeng.2015.08.345

6. V.V. Karetnikov, A.A. Sikarev, River transport (XXI century), 1(43), 65-68 (2010)

7. V.A. Bekryashev, V.V. Karetnikov, River transport (XXI century), 2(67), 49-53 (2014)

8. V.V. Karetnikov, A.A. Sikarev, Journal of the University of Water Communications, $\mathbf{3}$, 93-96 (2010)

9. V.V. Karetnikov, A.A. Sikarev, S.F. Shakhnov, Automation of navigation (St. Petersburg, GUMRF, 2014)

10. V.V. Karetnikov, V.A. Bekryashev, River transport (XXI century), 1(66), 30-33 (2014)

11. V.V. Karetnikov, R.V. Volkov, Yu.V. Yatsuk, River transport (XXI century), 1(77), 4648 (2016)

12. V.V. Karetnikov, D.F. Milyakov, S.V. Rudykh, River transport (XXI century), 5(76), 35-37 (2015)

13. J.Y. Roh, M.S. Shin, Y.C. Suh, I.T. Yang, D.H. Lee, The 2nd International Water Safety Symposium. Journal of Coastal Research, Special Issue, 79, 319-323 (Coconut Creek, Florida, 2017). https://doi.org/10.2112/SI79-065.1

14. V. Karetnikov, E. Ratner, A. Ageeva, AFRICON, 2017 IEEE, 1479-1484 (IEEE, 2017). https://doi.org/10.1109/AFRCON.2017.8095700 